www.jmscr.igmpublication.org

Index Copernicus Value: 79.54

ISSN (e)-2347-176x ISSN (p) 2455-0450

crossrefDOI: https://dx.doi.org/10.18535/jmscr/v7i2.52

\title{
Success of NIV in Acute exacerbation of COPD and Factors Associated with Failure- A Cross Sectional Study in a Tertiary Care Centre
}

\author{
Authors \\ Anitha Thilakan ${ }^{1 *}$, Anithakumari $K^{2}$, Reshmi S Nair ${ }^{3}$, Sanjeev Nair ${ }^{4}$ \\ ${ }^{1}$ Department of Pulmonary Medicine, Govt Medical College Ernakulam \\ ${ }^{2,3,4}$ Dept of Pulmonary Medicine, Govt Medical College Thiruvananthapuram \\ *Corresponding Author \\ Dr Anitha Thilakan \\ Asst Professor, Dept of Pulmonary Medicine,Govt Medical College Ernakulam \\ HMT Colony PO, Kalamassery, Ernakulam, Kerala PIN-683503, India \\ Ph: 9497265709, Email: anithathilakan@gmail.com
}

\begin{abstract}
Background: Non invasive ventilation has been helpful in managing COPD patients presenting with Acute exacerbations. This study tries to find out the success rate and factors associated with failure of NIV in AECOPD with Acute or chronic respiratory failure.

Methods: COPD Patients admitted with acute or chronic respiratory failure to the Intensive respiratory care unit started on NIV BiPAP mode using ICU ventilator were enrolled into the study. Patients were followed up till either they were weaned off NIV or ended up with intubation. Patients were followed up with serial $A B G$ s and intense clinical monitoring according to Department protocol.

Setting: Department of Pulmonary Medicine, Govt Medical College Thiruvananthapuram.

Result: NIV was successful in $72 \%$ of patients with Acute exacerbation of COPD. Patients with an initial low respiratory rate, high GCS score ans less severe airflow obstruction had a better outcome with NIV. An improvement in the blood gas values within the first $1 \mathrm{hr}$ of initiating NIV contributed to a successful final outcome.

Conclusion: When initiated sufficiently early Non Invasive ventilation is a better choice in acute exacerbations of COPD with respiratory failure. Carefull patient selection leads to better outcome and reduces complications.
\end{abstract}

Keywords: Chronic Obstructive Pulmonary Disease, Acute Exacerbation, Non invasive ventilation, Respiratory failure.

\section{Introduction}

Exacerbations in COPD are defined as acute worsening of respiratory symptoms that result in additional therapy ${ }^{[1]}$. Each exacerbation leads to significant morbidity and mortality ${ }^{[2]}$.
A considerable number of COPD exacerbations result in acute on chronic respiratory failure that may end up in endotracheal intubation and mechanical ventilation. Early initiation of NIV can improve the condition of the patient and prevent intubation associated complications ${ }^{[3]}$. This study 
tried to find out the success rate and factors associated with failure of NIV in Acute Exacerbation of COPD.

\section{Materials and Methods}

The study was conducted in the Intensive Respiratory care Unit of Dept of Pulmonary Medicine, Government Medical College Thiruvananthapuram for a period of 1 year. All consecutive COPD patients admitted in the IRCU with Acute exacerbation and acute on chronic respiratory failure were recruited into the study. 60 patients were enrolled in the study. Patients who had Acute Hypercapnoeic respiratory failure as per ABG, Conscious and cooperative, Hemodynamically stable, with good cough reflux were included. Patients who had a $\mathrm{pH}<7.1$, with history of recent Myocardial Infarction, Uncooperative or unconscious, hemodynamically unstable patients, those with copious secretion and facial injuries were excluded from the study. Demographic and clinical details were collected using a structured questionnaire soon after admission. Old records were scrutinized in case of patients previously treated at our facility. Vitals and Arterial Blood Gas was analysed during admission and patients with Respiratory Acidosis were started on BIPAP mode of ICU Ventilator following hospital protocol. Vitals and ABG were reassessed after half an hour , 1 hour and 6 hours of initiating NIV. Clinical condition of the patient was also assessed periodically. Those patients who tolerated NIV and showed improvement clinically and in the blood gases were continued on NIV. Those who did not tolerate NIV or clinical condition worsened were intubated according to standard procedure. Those patients who tolerated NIV or survived on NIV were considered as success. Those patients who could not tolerate mask or worsened clinically or showed worsening of acidosis leading to intubation were considered as failures.

\section{Analysis}

Data was coded \& entered in Microsoft Excel \& statistical analysis was done, using statistical software SPSS version 15.0.Quantitative variables were summarized as Mean \& Standard deviation.

95\% Confidence Interval was estimated. Qualitative variables were summarized as frequency \& Percentage. Univariate analysis was done to find the association of each parameter to the final outcome. Multivariate analysis was performed to find association with outcome when all the paramaeters were combined together.

\section{Ethical Issues}

The study was initiated after obtaining clearance from The Institutional Ethics Committee. Informed consent was obtained from relatives prior to recruitment to the study. Control group could not be kept as depriving seriously ill patients of the accepted treatment protocol would be against Medical Ethics.

\section{Results}

60 patients were recruited into the study of which $78 \%$ were males and $22 \%$ females. NIV was successful in $43(72 \%)$ while $17(28 \%$ ) failed on NIV. Mortality was $18 \%$ among those intubated. The mean age of patients in whom NIV was successful was $60.95 \mathrm{yrs}$ and $65.94 \mathrm{yrs}$ in failure group. The difference in the mean age was statistically significant $(p=0.02)$. $45 \%$ of recruited patients belonged to the age group of 60-69yrs. Univariate analysis was done to check association of individual parameters to success of NIV. Intubated patients had a mean respiratory rate of 37.88 breaths per minute. A respiratory rate less than 35 breaths per minute was associated with successful outcome. $(\mathrm{p}=<0.001)$. Patients with a GCS score of $>12 \mathrm{had}$ a successful outcome $(\mathrm{p}<0.001)$.Patients with serum albumin level $<3 \mathrm{gm} / \mathrm{dl}$ had a worse outcome when compared those with higher levels and the difference was statistically significant $(p<0.001)$. Patients who had improvement in the arterial $\mathrm{pH}$ after $1 \mathrm{hr}$ had a better success rate when compared to those whose value did not change or decreased while on NIV $(p<0.001)$.Similarly, patients who recovered on NIV had a significant drop in the PCO2 values after $1 \mathrm{hr}$ of initiation of 
$\mathrm{NIV}(\mathrm{p}<0.001)$.Patients who had mild to moderate severity of disease had a better chance for success on $\mathrm{NIV}(\mathrm{p}<0.001)$.

However on multivariate regression analysis, GCS, severe airflow limitation, initial $\mathrm{pH}, \mathrm{PCO} 2$ and change in $\mathrm{pH}$ and $\mathrm{PCO} 2$ after 1 hour of NIV showed significance $(\mathrm{p}<0.05)$.

Table-1 Age distribution

\begin{tabular}{|l|c|c|}
\hline Age (yrs) & No of Patients & \% \\
\hline $40-49$ & 2 & 3.3 \\
\hline $50-59$ & 19 & 31.7 \\
\hline $60-69$ & 27 & 45 \\
\hline $70-79$ & 11 & 18.3 \\
\hline$\geq 80$ & 1 & 1.7 \\
\hline Total & 60 & 100 \\
\hline
\end{tabular}

Table-2 Multivariate analysis

\begin{tabular}{|l|c|c|c|c|}
\hline Variable & Coefficient & Std error & F test & P value \\
\hline RR & 0.146 & 0.090 & 2.62 & 0.1112 \\
\hline Albumin & 0.021 & 0.081 & 0.06 & 0.7961 \\
\hline GCS & 0.308 & 0.109 & 8.01 & 0.0065 \\
\hline PFT & -0.221 & 0.088 & 6.35 & 0.0147 \\
\hline pH & 0.236 & 0.097 & 5.96 & 0.0179 \\
\hline dPCO2 & -0.025 & 0.002 & 13.4 & 0.0000 \\
\hline \multicolumn{1}{|c|}{$\mathbf{d ~ p H}$} & 0.221 & 0.095 & 5.37 & 0.0242 \\
\hline
\end{tabular}

$\mathrm{p}<0.05$

\section{Discussion}

Acute exacerbation of COPD in patients who are having chronic respiratory failure can be fatal if not intervened early enough. Even in patients with less severe disease, the rapid decline in lung function during an exacerbation along with other comorbidities may precipitate a life threatening event $^{[1,2]}$. Stratifying our patients based on their initial presentation during an exacerbation can help clinicians to decide on their further effective management ${ }^{[3]}$. This study was conducted to find out the success rate of NIV in AECOPD and also to find out the factors contributing to failure of non invasive ventilation.

$72 \%$ of our study population showed a successful outcome after initiation of NIV. The results are comparable with the already available studies ${ }^{[3-5]}$. Mortality among patients who were initiated on NIV was $18 \%$. Results were similar in study by Putinati et $\mathrm{al}^{[7,10]}$.
The mean age of patients who had a successful outcome with NIV in our study group was 60.95 years whereas it was 65.94 years in patients who failed on NIV.A younger age group had a higher chance of successful outcome similar to previous studies by Confalonierri et al ${ }^{[9]}$.

A lower respiratory rate at presentation improved the chances of success of NIV. The difference in mean initial respiratory rate among the intubated and non intubated patients was statistically significant $(\mathrm{p}<0.001)$. The earlier respiratory failure is identified and started on NIV, the better is the outcome.

This study group showed improvement in respiratory failure in patients who had a higher level of GCS score. $92.5 \%$ of patients who improved on NIV had a GCS of $>12$.An initial GCS of $>12$ was associated with a better outcome $(p<0.001)$. Confalonierri et al and few others found that a GCS $<11$ was associated with failure of $\mathrm{NIV}^{[9][20]}$.

Nutritional status of a patient has an important role in deciding the outcome of exacerbation in COPD. Hypoproteinemia affects the respiratory muscle strength and the ventilatory drive. Patients with a low serum albumin level had an adverse outcome in our study. S.Alb level of $<3 \mathrm{gm} / \mathrm{dl}$ was associated with an unfavourable outcome $(\mathrm{p}<0.001)$. Antonio et al in their study observed that a higher level of albumin was associated with a successful outcome using NIV ${ }^{[18]}$.

Arterial blood gas values at the time of presentation to the hospital affects the outcome of NIV. An initial low $\mathrm{pH}$ and high $\mathrm{PCO} 2$ values were associated with a high failure rate. The mean $\mathrm{pH}$ of patients who failed NIV was $7.25(\mathrm{p}<0.001)$. McLaughlin et al in their study found that a mean $\mathrm{pH}$ of $<7.25$ was associated with failure of $\mathrm{NIV}^{[17]}$. Several studies by Putinati et al ${ }^{[7]}$ and Antonio et $\mathrm{al}^{[18]}$ and many others showed a similar result ${ }^{[20,21]}$.

An improvement in the $\mathrm{pH}$ and $\mathrm{PCO} 2$ values after 1 $\mathrm{hr}$ of initiation of NIV also contributed to an improved outcome. The results were comparable to many previous studies ${ }^{[7][17][18][23]}$.

Our study included patients who were previously diagnosed as COPD according to GOLD guidelines 
and so the Severity of disease was also taken into consideration during analysis. Patients with mild to moderate COPD showed a better outcome with NIV when compared to patients with more severe disease. The results were comparable with results of the study by Antonio et al ${ }^{[18]}$.

\section{Conclusion}

The observations from this study suggest that when initiated early enough Non Invasive Ventilation can avoid invasive ventilation in acute exacerbations of COPD. Patients should be selected based on the initial clinical presentation and the Blood gases so that seriously ill patients are not deprived of their time into invasive ventilation. Aggressive monitoring during initial hours of therapy with NIV is necessary to avoid complications and mortality.

\section{Acknowledgment}

I hereby acknowledge the help rendered by Dr Manjula VD, Prof and HOD Community Medicine in statistical analysis and interpretation.

\section{References}

1. Global Initiative for Obstructive Lung Disease-Global strategy for the diagnosis, management and prevention of chronic obstructive pulmonary disease:2018 report

2. Terence A. R. Seemungal, Gavin C. Donaldson, Elizabeth A. Paul, Janine C. Bestall, Donald J. Jeffries, And Jadwiga A. Wedzicha. Effect of Exacerbation on Quality of Life in Patients with Chronic Obstructive Pulmonary Disease .Am J Respir Crit Care Med .Vol 157. pp 1418-1422, 1998

3. Non-invasive ventilation in acute respiratory failure. British Thoracic Society Standards of Care Committee. Thorax 2002;57:192211

4. Ambrosino N. Noninvasive mechanical ventilation in acute on chronic respiratory failure: determinants of success or failure. Monaldi Archives for Chest Disease 1997;52(1):73-75.
5. Kramer N, Meyer TJ, Meharg J, Cece RD, Hill NS. Randomized, prospective trial of noninvasive positive pressure ventilation in acute respiratory failure .American Journal of Respiratory \& Critical Care Medicine 1995;151(6):1799-1806.

6. Stephan Budweiser, Rudolf A Jörres, Michael Pfeifer. Treatment of respiratory failure in COPD. Int $\mathbf{J}$ Chron Obstruct Pulmon Dis. 2008 Dec; 3(4): 605-618.

7. S Putinati,L Ballerin, M Piattella, G.L Panella, A Potena. Is It Possible To Predict The Success Of Non-Invasive Positive Pressure Ventilation In Acute Respiratory Failure Due To Copd?.Respiratory Medicine October 2000volume 94, Issue 10, Pages 997-1001

8. D Chiumello,G Conti,G Foti,M Giacomini Matteo, A Braschi, G Iapichino.Non Invasive ventilation outside the intensive care unit for Acute Respiratoty Failure. Minerva Anaestesiol 20009;75:459-66

9. M. Confalonieri, G.Garuti, M.S. Cattaruzza, J.F. Osborn, M.Antonelli, G. Conti.A chart of failure risk for noninvasive ventilation in patients with COPD exacerbation. Eur Respir J 2005; 25: 348-355.DOI: 10.1183/09031936.05.00085304

10. Annalisa Carlucci, Jean-Christophe Richard, Marc Wysocki, Eric Lepage, Laurent Brochard And The Srlf Collaborative Group On Mechanical Ventilation .Noninvasive Versus Conventional Mechanical Ventilation An Epidemiologic Survey .Am J Respir Crit Care Med Vol 163. Pp 874-880, 2001

11. P K Plant, J L Owen,M W Elliott. Noninvasive ventilation in acute exacerbations of chronic obstructive pulmonary disease: long term survival and predictors of inhospital outcome Thorax 2001;56:708-712

12. Maurizio Moretti, Carmela Cilione, Auro Tampieri, Claudio Fracchia, Alessandro Marchioni, Stefano Nava .Incidence and causes of non-invasive mechanical 
ventilation failure after initial success. Thorax 2000;55:819-825

13. Ritesh Agarwal, Rajesh Gupta, Ashutosh N, Aggarwal, Dheeraj Gupta. Noninvasive positive pressure ventilation in acute respiratory failure due to COPD vs other causes: Effectiveness and predictors of failure in a respiratory ICU in North India. International Journal of COPD 2008:3(4) 737-743

14. Josephine V Lightowler, Jadwiga A Wedzicha, Mark W Elliott, Felix SF Ram. Non-invasive positive pressure ventilation to treat respiratory failure resulting from exacerbations of chronic obstructive pulmonary disease: Cochrane systematic review and meta-analysis. BMJ Volume 326 25 January 2003 bmj.com

15. Helmy Haja Mydin, Stephen Murphy, Howell Clague, Kishore Sridharan, Ian K Taylor. Anemia and performance status as prognostic markers in acute hypercapnic respiratory failure due to chronic obstructive pulmonary disease. International Journal of COPD 2013:8 151-157

16. Char-Wen Chen,Yih-Yuan Chen,Chin-Li Lu, Solomon Chih-Cheng Chen,Yi-Jen Chen, Ming-Shian Lin,Wei Chen. Severe hypoalbuminemia is a strong independent risk factor for acute respiratory failure in COPD: a nationwide cohort study. International Journal of COPD 2015:10 1147-1154

17. K.M. Mclaughlin, I.M. Murray , G. Thain And G.P. Currie.Ward-based non-invasive ventilation for hypercapnic exacerbations of COPD: a 'real-life' perspective. Q J Med 2010; 103:505-510. doi:10.1093/qjmed/hcq063

18. Antonio Anto' n, MD; Rosa Gu“ ell, MD; Juan Go'mez, MD; Jose' Serrano, MD; Abilio Castellano, MD; Jose Luis Carrasco, BSC; and Joaqui'n Sanchis, MD. Predicting the Result of Noninvasive Ventilation in Severe Acute Exacerbations of Patients With
Chronic Airflow Limitation. CHEST / 117 /

3 / March, 2000;828-33

19. Laurence Vignaux,Frédéric Vargas,Jean Roe seler, Didier Tassaux, Arnaud W. Thille, Michel P. Kossowsky, Laurent Brochard, Philippe Jolliet. Patient-ventilator asynchrony during non-invasive ventilation for acute respiratory failure: a multicenter study. Intensive Care Medicine. May 2009, 35:840

20. Irfan Ucgun, Muzaffer Metintas, Hale Moral, Fusun Alatas, Huseyin Yildirim, Sinan Erginel. Predictors of hospital outcome and intubation in COPD patients admitted to the respiratory ICU for acute hypercapnic respiratory failure. Respiratory Medicine Volume 100, Issue 1, January 2006, Pages 66-74

21. Contou D, Fragnoli C, Córdoba-Izquierdo A, Boissier F, Brun-Buisson C, Thille AW. Non invasive ventilation for acute hypercapnic respiratory failure: intubation rate in an experienced unit. Respir Care. 2013 Dec;58(12):2045-52. doi: 10.4187/respcare.02456.

22. Ingrid $L$ Titlestad, Annmarie $T$ Lassen, Jørgen Vestbo Long-term survival for COPD patients receiving noninvasive ventilation for acute respiratory failure.Int $\mathrm{J}$ Chron Obstruct Pulmon Dis. 2013; 8: 215-219. doi: 10.2147/COPD.S42632

23. J V J Lightowler, M W Elliott.Predicting the outcome from NIV for acute exacerbations of COPD .Thorax2000;55:815-816.

\footnotetext{
Abbreviations

COPD-Chronic Obstructive Pulmonary Disease, AECOPD-Acute Exacerbation of COPD,NIV-Non Invasive Ventilation, BIPAP-Bi level Positive Airway Pressure, IRCU-Intensive Respiratory Care Unit, ABG-Arterial Blood Gas, GCS-Glasgow Coma Scale
} 